\title{
THE EFFICACY OF HONEY AS AN ALTERNATIVE TO STANDARD ANTISEPTIC CARE IN THE TREATMENT OF CHRONIC PRESSURE ULCERS AND DIABETIC FOOT ULCERS IN ADULTS
}

\author{
GF PEREIRA*, M BALMITH, M NELL
}

Department of Pharmacology, School of Medicine, Faculty of Health Sciences, University of Pretoria, Private Bag X323, Arcadia 0007, Pretoria, South Africa. E-mail: u18006991@tuks.co.za

Received: 30 June 2021, Revised and Accepted: 17 September 2021

\section{ABSTRACT}

Objective: A chronic wound fails to progress through the phases of wound healing in an orderly and appropriate process, and poses a major challenge to wound care professionals. Pressure ulcers (PUs) and diabetic foot ulcers (DFUs) are classified as chronic wounds. Antiseptics, such as povidoneiodine (PVP-I), are often used to treat bacterial infections in chronic wounds; however, their efficacy and ability to accelerate wound healing has come into question. As a result, current medical research is now focusing on alternative and natural antiseptic agents, such as honey, for the treatment of chronic wounds. The aim of this study was to analyze the wound healing effects of honey in PU and DFU treatment in comparison to standard antiseptic care.

Methods: A systematic literature search of PubMed, ScienceDirect, and ClinicalKey was conducted to identify all published data of clinical trials and narrative reviews that investigated or reported the use of honey and standard antiseptics in the treatment of PUs and DFUs in adults. A keyword search was then performed using the following keywords: "PUs", “DFUs”, “antiseptics", "PVP-I”, "honey”, "Manuka honey (MH)”, and "wound healing”. Database restrictions were implemented based on the inclusion and exclusion criteria, notably the report's availability, completion status and language, the sample populations' age, as well as, the date of publication. A preferred reporting item for systematic review and meta-analysis (preferred reporting items for systematic reviews and meta-analyzes) diagram was constructed illustrating the study selection process. The eligibility of articles was assessed by the screening of titles, abstracts and full texts. A total of 12 articles were included in this study comprising of 775 patients with PUs, DFUs or a combination of PUs and DFUs.

Results: Results indicated that honey reduced bacterial infection, reduced pain and edema experienced by patients, reduced the odor of the wound and promoted wound healing in the treatment of chronic ulcers. Honey was also found to be effective in the process of debridement and exudate removal.

Conclusion: Honey was found to be highly effective in the treatment of PUs and DFUs and should be considered as an alternative to standard antiseptic care in the treatment of chronic wounds. However, the literature in this study is limited and so further research into honey and its antiseptic-promoting activity in wound healing is recommended.

Keywords: Pressure ulcers, Diabetic foot ulcers, Antiseptics, Povidone-iodine, Honey, Wound healing.

(C) 2021 The Authors. Published by Innovare Academic Sciences Pvt Ltd. This is an open access article under the CC BY license (http://creativecommons.org/ licenses/by/4.0/) DOI: http://dx.doi.org/10.22159/ajpcr.2021v14i11.42560. Journal homepage: https://innovareacademics.in/journals/index.php/ajpcr

\section{INTRODUCTION}

Normal wound healing consists of four stages: hemostasis, inflammation, proliferation, and remodeling. Chronic wounds develop and are slow to heal as a result of an interruption in the normal healing process $[1,2]$. Chronic wounds do not progress past the inflammatory phase and are characterized by heat, redness, pain, and swelling [1] and are associated with long hospital stays and high medical costs [2]. The frequency of patients living with chronic wounds is relatively high globally, with an average of 120 per 100,000 people [2]. The prevalence of chronic wounds increases with age and are frequently found in older people [2]. Pressure ulcers (PUs) and diabetic foot ulcers (DFUs) are classified as chronic wounds and place a high burden on health care systems. This review will focus on the treatment of these wounds as they share comparable pathogeneses that is a combination of decreased angiogenic response and increased pressure [3].

Hospital-acquired PUs are localized areas of damage to the skin and soft, underlying tissue over bony prominences and develop due to pressure and reduced blood circulation [1]. These injuries occur in $3-34 \%$ of hospitalized patients globally and often affect patients who are immobile, bedridden, suffer from cognitive impairment or have underlying comorbidities [1,3].
DFUs are open wounds that develop in patients with diabetes mellitus (DM) [4-6] due to damaged capillaries, hyperglycemia, nerve damage and a compromised immune system resulting in small, benign wounds that become infected [5]. The global DFU prevalence is $6.3 \%$, of which a third may result in amputation [4]. DFUs develop on the plantar aspect of the foot causing permanent nerve damage and may result in amputation of the lower limb [6].

PUs and DFUs impede blood flow, reduce nutrient supply, and deprive tissues of oxygen resulting in the accumulation of toxic waste products and the development of localized ischemia, tissue inflammation and shearing [7]. Chronic wounds pose a major challenge to wound care professionals as the treatment process is complex, time-consuming and costly $[7,8]$. Morbidity is high in patients with these types of wounds and the cost associated with chronic wound treatment highlights the necessity to branch into alternative wound treatment options.

This review aims to analyze the efficacy of honey as an alternative to standard antiseptic care, such as povidone-iodine (PVP-I), in the treatment of Pus and DFUs. Complete wound healing can be achieved if they are detected early and if the appropriate treatment method is applied $[2,8]$. If these wounds are not treated properly, they may become fatal [2]. Various intrinsic and extrinsic factors contribute to the development and pathogenesis of these chronic wounds and 
need to be identified before any treatment can be considered [2] as they work in combination in the formation of these types of wounds $[5,6,8]$.

\section{RISK FACTORS}

\section{PUs}

Intrinsic risk factors

Intrinsic, predisposing (patient-related) factors influence the supporting structures of the skin and the lymphatic system [9]. These factors severely affect the ability of soft tissue and skin to withstand uninterrupted external forces [9]. Maintaining good nutrition and hydration supports blood flow to wounded tissue and prevents fragile skin breakdown [10]. Patients suffering from nutritional deficiencies, such as malnutrition or anemia, are more susceptible to PU formation [11]. Hence, it is recommended that patients follow a high-protein, vitamin C-, iron- and zinc-rich diet [11]. These recommendations may vary and are carefully adjusted according to the presence of any underlying comorbidities and the patient's health status $[10,12]$. Sufficient oxygen supply is required for all stages of wound healing, which implies that patients with cardiac disease, diabetes or patients with hypercholesterolemia are more susceptible to PU formation as their oxygen levels may be compromised [12]. Spinal cord injuries, arthropathies, or progressive neurological disorders (Parkinson disease, sclerosis and Alzheimer disease) are conditions that increase the patient's risk to primary external factors such as paralysis and/or loss of feeling and may result in PU formation [10,12]. The patients who suffer from neurological diseases (depression or psychosis) are more susceptible to PU development as a result of poor diet, secondary physical health conditions (i.e., diabetes) or the tendency to neglect personal hygiene (incontinence), thus making the skin more vulnerable to infection and maceration $[10,11,12]$

\section{Extrinsic risk factors}

Extrinsic factors include direct pressure, friction and shear force [8]. These forces compress soft tissues against bony prominences and slow down capillary blood flow to local tissue [8]. They shear and tear blood vessels to the point where oxygen supply to the tissue is halted [13]. Moisture is another extrinsic risk factor that alters the resistance of the epidermis by reducing its tensile force, softening the surface of the skin and altering the cutaneous chemical environment, which makes the skin susceptible to maceration by external forces, injury and ulceration [8]. Once these factors have been identified, interventions to prevent the development of PUs can be applied.

\section{DFUs}

There are several common risk factors amongst diabetic patients that contribute to the development of DFUs [14]. The two largest contributing factors for DFU development are peripheral neuropathy and peripheral vascular disease (PVD) [14]. Peripheral neuropathy involves damage to nerve endings in lower limbs owing to the high blood glucose levels and is common in diabetic patients [14]. The patients experience disconnections from normal sensations, such as numbness, pain, or altered vibrations. Neuropathy in the peripheral limbs increases the risk for the development of lesions which may progress to ulcers owing to the lack of feeling in these regions [14]. PVD is a circulatory disorder that reduces blood flow and constricts blood vessels (the aortoiliac segment and the superficial femoral artery) in the lower extremities [14]. PVD slows down the rate of healing and is a major risk factor for lower-limb amputation [14]. DFUs are open wounds that have a high risk for infection $[14,15]$ which may become systemic and enter the bloodstream and bone which can result in amputation and death [14,15]. Obesity, hypertension, smoking, insulin usage, poor glucose control or poor footwear that causes skin breakdown, are some of the lifestyle risk factors that contribute to the development of DFUs [14]. Arterial insufficiency, limited joint mobility (Charcot joint) and previous foot ulcerations or lower extremity amputations are additional contributing factors that result in DFU formation and impaired wound healing [14].

\section{INTERVENTIONS}

\section{Interventions preventing the development of PUs}

Several scales and scoring methods have been developed to quantify a person's risk of PU development by identifying the presence of risk factors. The Braden-, Norton-, and the Waterlow scale are three of the most widely used tools for risk assessment $[10,11]$. In combination with these tools, regular skin assessments are vital. Hospital-acquired PUs are common in the patients who are limited in their movement, especially geriatrics [12]. The promotion of movement, repositioning methods and alternate support surfaces, such as sheepskin, are used in combination with wound management strategies to reduce external pressures on the affected area $[11,13]$. The use of skin moisturisers and prophylactic foam dressings are also advised [11-13]. Nutritional deficiencies should be identified and rectified as malnutrition may contribute to PU development [13]. Paralyzed patients in wheelchairs are encouraged to shift their weight often and to sit on foam or gel cushions to reduce pressure [13]. The correct management of incontinence is essential, as urine or fecal matter contain acids and enzymes which may cause skin excoriation [13]. Incontinence in combination with limited mobility increases the risk for the development of PUs [13].

\section{Interventions preventing the development of DFUs}

Prevention assessments and techniques are essential to prevent the development of DFUs and avoid possible amputation $[15,16]$. Daily inspections, instructions on foot hygiene and wearing proper footwear are a few interventions that the patient can carry out themselves [15]. The patients who are at high risk for foot ulcers are provided with therapeutic shoes with pressure-relieving insoles [15]. Nutritional deficiencies delay the wound healing process and healthcare professionals need to ensure that patients meet the dietary requirements to ensure successful healing during treatment [15]. Obesity is a risk factor for DFU development as it increases stress on the feet and reduces blood flow, therefore maintaining a healthy weight is important to prevent blood occlusions, blisters and cuts $[14,15]$. Tobacco products have been linked to circulatory problems and contain chemicals that may slow down healing [14], thus cessation of smoking is recommended [14]. Daily blood-glucose level monitoring in the patients with diabetes is essential as high glucose levels may lead to further foot complications and difficulty in healing $[15,16]$. Medical professionals and primary caregivers need to carry out regular foot-care examinations to detect any developing lesions or sores regularly [14-16].

The development and manifestation of PUs and DFUs is complex and multifactorial $[8,9]$. In many cases, preventative interventions are not applied in time to prevent the formation of a chronic ulcer and a patient may present with an ulcer that is progressive $[8,9,14,16]$. It is therefore of utmost importance to promptly determine the stage of the PU or DFU to start the appropriate treatment that will aid in wound healing.

\section{CLASSIFICATIONS OF ULCERS}

\section{Stages of PUs}

The National PUs Advisory Panel categorized PUs into different stages (Table 1). Originally, there were four (I-IV) stages however, two new categories were recently introduced namely, deep tissue injury and unstageable PUs [9]. The stages of the PUs are grouped by the severity of symptoms, depth of the damage and the presentation of the wound [9]. To determine the stage of the PU; slough, exudate and eschar should be removed to expose the base of the wound [9]

PUs are wounds that develop in the upper layers of the skin owing to sustained pressure, that eventually extends outward and downward into the deeper tissue layers [1,3]. Higher graded ulcers present the greatest risk of infection [1,3]. Stage II-IV PUs are often characterized by an inflammatory reaction as well as systemic infection or local bacterial colonization $[1,3,11]$. If not treated correctly or early enough the wound can become severely infected and may require additional systemic antibiotics [3,11]. Stage III and IV PUs present with slough 
Table 1: Stages of PUs according to NPUAP

\begin{tabular}{|c|c|}
\hline Stage & Description \\
\hline Stage I & $\begin{array}{l}\text { Non-blanchable erythema of intact skin, } \\
\text { indicating an interruption in blood flow to the } \\
\text { skin [11]. The skin appears redder, warmer and } \\
\text { firmer than usual. The color change may indicate } \\
\text { the beginning of a serious injury to the deep } \\
\text { tissue [11]. }\end{array}$ \\
\hline Stage II & $\begin{array}{l}\text { Partial-thickness loss of the epidermis, dermis } \\
\text { or both }[11,12] . \text { The ulcer presents as a shallow, } \\
\text { pus-filled, open wound with a red/pink wound } \\
\text { bed }[11,12] .\end{array}$ \\
\hline Stage III & $\begin{array}{l}\text { The ulcer develops underneath the skin } \\
\text { and presents as a crater with slough and } \\
\text { exudate }[11,12] \text {. }\end{array}$ \\
\hline Stage IV & $\begin{array}{l}\text { This is the most severe stage of ulcer } \\
\text { development. The dermis is severely damaged } \\
\text { and recedes into the muscle and bone. The } \\
\text { wound is black in color, with eschar, and } \\
\text { infection }[11,12] \text {. }\end{array}$ \\
\hline $\begin{array}{l}\text { Suspected deep } \\
\text { tissue injury }\end{array}$ & $\begin{array}{l}\text { Injuries that develop deep below discolored } \\
\text { skin [11]. A blood-filled blister may develop [11]. }\end{array}$ \\
\hline Unstageable PU & $\begin{array}{l}\text { The bottom of the wound bed is covered in slough } \\
\text { and eschar [11]. There is extensive tissue damage } \\
\text { with full-thickness tissue loss [11]. The stage } \\
\text { of the wound can only be determined once the } \\
\text { wound has been debrided [11]. }\end{array}$ \\
\hline
\end{tabular}

and exudate that may require additional debridement techniques to correctly treat the wound and prevent infection $[1,3,11]$. 'Suspected deep tissue injury' and 'Unstageable PU', were introduced to assist with documentation and classification of the wound [11]. PUs in either of these two categories must be treated immediately with preventative therapeutic measures [11].

\section{Grading of DFUs}

The classification of DFUs can provide a reasoned approach to treatment options and can assist in predicting the outcome thereof [15]. There are several classification systems regarding DFUs; however, the Wager ulcer classification system is most widely used (Table 2) [15]. This system classifies DFUs from grades $0-5$ based on the depth of the wound; the presence of gangrene or osteomyelitis and the severity of tissue necrosis [15]. It, unfortunately, does not make provision for ischemia and infection which may be present [15].

DFUs must be detected early enough to prevent the development of a severe injury that may result in amputation $[4,5,15]$. Grade 0 DFUs are the least severe and can be treated accordingly if they are detected early. However, most patients present with Grade 1 or 2 DFUs as patients only recognize the development of a serious injury once the subcutaneous tissue is exposed [15]. This supports the need for patients, who are diabetic and susceptible to DFU formation, to complete regular foot examinations and monitor their blood sugar levels carefully as failure to do so, will increase the risk of ulcer formation. Grade 4 and 5 DFUs are the most severe and present with extensive damage. Gangrene and necrotic tissue are present in these wounds which increases bacterial growth and infection. If left untreated or if the incorrect treatment method is applied to these wounds, amputation will be required.

\section{TREATMENT OF ULCERS}

\section{Treatment of PUs}

The treatment of PUs is challenging as these wounds can become chronic and give rise to several complications such as sepsis, abscesses, joint and bone infections and cellulitis $[7,17]$. There are several treatment options available to manage PUs and avoid secondary conditions [17]. Surgical debridement is sometimes necessary to remove necrotic tissue [7]. Topical or systemic, antibiotics and antiseptics may be administered to treat
Table 2: Grading of DFUs according to the Wagner ulcer classification system

\begin{tabular}{ll}
\hline Grade & Description \\
\hline Grade 0 & $\begin{array}{l}\text { Intact skin in patients who are at high risk [15]. } \\
\text { Grade 1 }\end{array}$ \\
$\begin{array}{l}\text { Ulcers are superficial with exposed subcutaneous } \\
\text { tissue [15]. }\end{array}$ \\
Grade 2 & $\begin{array}{l}\text { Ulcers extend to the ligament, tendon or fascia without } \\
\text { abscess formation or osteomyelitis [15]. }\end{array}$ \\
Grade 3 & $\begin{array}{l}\text { Ulcer extends to the deep tissue and present with } \\
\text { osteomyelitis and abscesses [15]. }\end{array}$ \\
Grade 4 & $\begin{array}{l}\text { Ulcers present with localized gangrene on patched parts of } \\
\text { the forefoot or the heel [15]. }\end{array}$ \\
Grade 5 & $\begin{array}{l}\text { Ulcers are the most severe and extensive as they present } \\
\text { with extensive gangrene in the whole foot [15]. }\end{array}$ \\
\hline
\end{tabular}

infected PUs and reduce microbial colonization [17]. Infection is a major challenge in PU treatment and may cause bacteremia and septicemia [7].

\section{Treatment of DFUs}

DFUs treatment focuses on offloading, debridement and wound closure without infection [18]. The relief of pressure and elevation of the infected foot are essential components during treatment $[15,18]$. Offloading includes patients using wheelchairs or crutches to completely prevent pressure exerted on the affected foot [18]. Total contact casts [18] are used to reduce pressure and its application has shown to be successful. Physicians, clinicians, and wound specialists often use different debridement techniques to remove any dead skin, foreign bodies or callus within the wound as these may contribute to infection and malodor of the wound $[14,15,18]$. Debridement also reduces the pressure exerted on the wound that may contribute to impeding wound closure and healing $[15,18]$. If the ulcer is not correctly debrided, it may increase the risk of amputation of the lower limb [18]. Wound dressings are necessary to absorb excess fluid, prevent tissue desiccation, and protect the wound from contamination $[15,18]$. The management and successful treatment of an ulcer are determined by its severity and presence of infection [15]. Often, DFUs are polymicrobial, which necessitates the use of antimicrobial and antiseptic impregnated wound dressings $[15,18]$. Osteomyelitis, cellulitis and localized infections are common in DFU affected patients; therefore, the correct antiseptic must be applied to the wound $[15,18]$.

Antiseptics are commonly used in PU and DFU treatment to inhibit the growth and development of bacteria and assist in wound healing [7]. Different types of antiseptics are available and vary in cost, effectiveness, use and side effects [7]. Drug and antiseptic-resistant bacteria pose an increased challenge in the successful treatment of PUs and DFUs, which accentuates the need for effective antiseptics to be selected to ensure that successful wound healing can be achieved.

\section{ANTISEPTICS}

Antiseptics are broad-spectrum agents that are effective against Grampositive and Gram-negative bacteria [7,19]. The ideal antiseptic should have several characteristics namely, (i) it must be active against viruses, fungi and spores; (ii) be bactericidal and not just bacteriostatic; (iii) have an accumulative effect and act rapidly; (iv) not exert irritation and toxic effects in the wound bed; (v) be soluble in water; (vi) persist over time and not become susceptible to contamination; (vii) be successful in the drying, debriding and cleansing of wounds; and (viii) be costeffective $[7,19]$. Different antiseptic-impregnated wound dressings are used, such as chlorhexidine, pyodine, silver sulfadiazine, cadexomer iodine, and PVP-I [19]. The choice of the type of antiseptic used will depend on the grading or staging of the ulcer and the secondary conditions that the patient may present with.

\section{PVP-I}

PVP-I, also known as pyodine or iodopovidone, is a commonly used antiseptic for the treatment of burns, infected wounds, PUs and 
DFUs [20]. It is a broad-spectrum, water-soluble polymer comprised of povidone, hydrogen iodide and iodine [21]. PVP-I's antimicrobial action occurs after iodine segregates from the polymer complex $[20,21]$. Once in the free form, iodine rapidly penetrates microbial cell membranes and interacts with nucleotides, proteins, and fatty acids which ultimately results in rapid cell death [20,21]. PVP-I might cause several adverse effects such as irritation, staining and swelling of the skin, and edematous erythema [21]. It is contraindicated in patients with thyroid-related diseases (i.e., hyperthyroidism), renal impairment or pregnant women [21]. Many researchers believe that PVP-I may have a deleterious effect on healing tissue due to the strong bactericidal effects of its iodine preparation [21]. This antiseptic also requires secondary dressings, such as hydrocolloids or hydrogels, for it to be effective in the treatment of infected PUs and DFUs [20]. PVP-I is the main antiseptic of interest in this study as its efficacy in the treatment of ulcers has been studied and noted in several clinical trials and reviews.

The healing process of PUs and DFUs is complicated by the widespread development of antimicrobial and antiseptic-resistant bacterial infections, causing antiseptic treatment to become less effective [19]. The use of certain antiseptics, such as PVP-I, do not necessarily meet the requirements to eradicate bacterial infections [19], which opens the possibility for the use of alternative and more natural antiseptic agents, such as honey, for the treatment of PUs and DFUs. The composition of honey and its physical and chemical properties which give rise to its ability to counter microorganisms located in the wound bed of infected PUs and DFUs in comparison to conventional antiseptics, have been thoroughly studied [19]. Promising results have been obtained regarding the antiseptic and antimicrobial activity of honey [19] and can also be used in combination with antibiotics or wound dressings to further enhance its activity. It has been approved as a therapeutic alternative for treatment against antibiotic-resistant bacteria based on its in vitro and in vivo efficacy [19]. This review will focus on honey's antiseptic efficacy, its use in the treatment of infected PUs and DFUs and its molecular and physical properties that give rise to its ability to promote wound healing in the treatment of PUs and DFUs.

\section{HONEY}

Scientists have been exploring the various bioactivities of honey which may cohesively expedite the healing process of chronic wounds more effectively in comparison to current therapeutics. Honey is a supersaturated sugar solution composed of 180 different compounds which contribute to its effectiveness [22]. The main components of honey include various sugars, water, and proteins [22,23]. Flavonoids and phenolic acids within honey are believed to determine its antimicrobial and antioxidant activities [23]. Several other factors have been found to contribute to the antimicrobial activity of honey, such as its low water content and high sugar concentration, which aids in providing a protective barrier to prevent infection [22,23]. Honey's mild acidity and hydrogen peroxide $\left(\mathrm{H}_{2} \mathrm{O}_{2}\right)$ content provide additional antimicrobial effects that aid in bacterial decolonization in wounds [23]. Different types of honey are available and their compositions may differ depending on where they were harvested as well as whether they have undergone chemical sterilization or not. Natural and floral honeys have been widely studied and applied to wounds; however, raw honey's high sugar content makes it susceptible to crystallization [22]. Water is released during the process of crystallization which allows yeast and bacteria to initiate fermentation within the honey [22]. In addition, at elevated temperatures, the peroxide activity in honey can be destroyed and its antimicrobial effects can be limited [22,23]. However, honey derived from the Leptospermum tree retains its antimicrobial activity in the presence of such high temperatures and are known as non-peroxide honey [22,23]. MH is a medical-grade, Leptospermum derived honey [22,23] which has been shown to have lesser side effects, and it can be used in the majority of patients undergoing PU and DFU treatment.

\section{MH}

$\mathrm{MH}$ is a mono-floral honey that is exclusively derived from the Leptospermum scoparium tree in New Zealand [24]. MH contains methylglyoxal which acts as an additional antimicrobial agent as it destroys bacterial flagella thus limiting the organism's ability to move and adhere to surfaces [25]. It also exerts non-peroxide antimicrobial activity (NPA) $[19,25]$. NPA is the measure of MH's ability to inhibit microbial growth [19,25]. Its NPA is measured and graded by the Unique Manuka Factor (UMF) [19]. The higher the UMF grading, the higher the antiseptic properties within the honey [19]. MH has shown promising in vivo activity in PU and DFU treatment owing to its chemical properties [19,25]. $\mathrm{MH}$ is also well-known for its ability to lower the $\mathrm{pH}$ of a wound, clear wound exudate, maintain hydration and inflammation of the wound bed, accelerate wound healing and reduce the size of the wound $[19,21,25]$ Based on its wound-healing properties, honey may be an effective therapeutic agent in the treatment of PUs and DFUs.

Chemical properties of honey

The chemical properties of honey namely, its low pH (3.2-4.5) [23] and low $\mathrm{H}_{2} \mathrm{O}_{2}$ content, makes it an effective antibacterial and antimicrobial agent that can assist in wound healing [22,23]. Honey is also able to activate inflammatory cells, such as neutrophils, which aids in the removal of bacteria and damaged tissue indicating that it has effective debridement abilities [23]. Through the use of autolytic debridement, honey uses its strong osmotic power to move lymphatic fluid from subcutaneous tissue into scar tissue. As a result, damaged and necrotic tissue is removed [23]. Neutrophils also assist in collagen and elastase deposition which promote wound healing and tissue regeneration $[22,23]$. Honey upregulates vascular homeostasis and angiogenesis within the wound, which provides blood, nutrients and oxygen to proliferating cells involved in tissue formation $[22,23]$. As a result, honey is effective in reducing wound size and improving the rate of novel tissue deposition. Honey is also known to aid in pain relief and was shown to exhibit anti-odor effects [22,23]. The mechanisms behind honey's antibacterial, anti-inflammatory, antioxidant debridement, pain-relief, and epithelialization-promoting effects will be analyzed further in this review [22].

\section{MATERIALS AND METHODS}

\section{Search strategy for data sources}

A systematic literature search was performed using ClinicalKey, Cochrane Library, Clinicaltrials.gov, PubMed, MEDLINE, and Science Direct. A keyword search was then performed using the following keywords: "PUs", "DFUs", "antiseptics", "PVP-I", "honey", "MH", and "wound healing". Boolean operators, "AND" and "OR" were used to make each search more precise and provide information that was most relevant to compile this review.

\section{Screening and data extraction}

Articles were screened according to the inclusion and exclusion criteria. All the studies relating to honey in the treatment of PUs and DFUs were included in the present review. The resulting and filtered articles were assessed using preferred reporting items for systematic reviews and meta-analyzes (PRISMA) diagram by removing articles that did not fall within the inclusion and exclusion criteria. In addition, duplicated articles were also removed by screening titles and abstracts. The abstracts of the remaining articles were further analyzed to identify whether they were relevant to be included in the study.

The inclusion of studies was determined by the author and corroborated by the co-authors based on eligibility criteria. To be included, studies had to be free full-text studies assessing the use of honey in the treatment of PUs and DFUs in adults. The study had to report on ages, the etiology of the ulcer, period of the study, and the application of both an antiseptic and honey.

\section{Inclusion criteria}

Only articles published in English were included in this study. Articles published between 2000 and 2021 were eligible and in vivo articles that included preclinical trials were also considered. Phase I- IV clinical trials in adults and articles that included clinical trials that occurred for longer than two (2) months were also included. Articles that were 
published in accredited and peer-reviewed journals and systematic and meta-analyzes reviews were used for this study.

\section{Exclusion criteria}

Articles not published in English and before 2000 were excluded. Articles with patients younger than eighteen (18) years of age were excluded due to ethical reasons. Articles that included preclinical clinical trials or clinical trials that did not occur for longer than two (2) months and included $<10$ (10) patients were excluded. Case report studies were also excluded.

A PRISMA diagram was constructed illustrating the study selection process (Fig. 1). The types of interventions used in the various studies were recorded. The duration of medical treatment, number of patients, and number of ulcers were retrieved from each study. The percentage of successful PU and DFU ulcer healing was recorded. The age of the patients was included to determine if they met the inclusion and exclusion criteria. The wound size and appearance of the wound were recorded before and after treatment to determine any positive outcomes.

A total of 3145 articles were retrieved of which 64 articles were eligible for inclusion after full-text screening. These articles provided qualitative and quantitative data, specifically on the framework of the efficacy of honey in the treatment of PUs and DFUs with antiseptics. Within the remaining articles, 12 articles provided quantitative and qualitative data, specifically addressing the comparison of honey and antiseptics in the treatment of PUs and DFUs. Relevant findings and associated statistical significance were extracted and summarized (Table 3). No statistical analysis was performed.

\section{RESULTS}

\section{PUs and DFUs}

In a randomized controlled trial (RCT) conducted by Gulati et al. (2014), the healing of chronic wounds with honey dressings in comparison to PVP-I dressings in adults was analyzed (Table 3) [21]. The trial was conducted over 6 weeks on adult patients. The majority of the PUs or DFUs had developed on the leg or ankle of the patients. The patients were randomized into two groups that is the honey group $(n=23)$ and the PVP-I group $(\mathrm{n}=22)$. After the 6-week follow-up period, 3 patients were excluded as 2 patients developed adverse effects to the PVP-I treatment and one patient failed to follow-up [21]. In the honey group, $31.82 \%$ of the patients achieved complete wound healing at the end of the 6 weeks whereas none $(0 \%)$ of the patients receiving PVP-I treatment attained complete wound healing [21]. The surface area and depth of ulcers increased with time thus treatment should aim to reduce the size and circumference of the wound [21]. The median surface area of the chronic wounds was recorded at the beginning and the end of the 6-weeks of treatment [21]. At week 0, the PVP-I group presented with a $4.25 \mathrm{~cm}^{2}$ median surface area wound which reduced to $1.95 \mathrm{~cm}^{2}$ at the end of week 6 [21]. In the honey group, the median surface area was $4.35 \mathrm{~cm}^{2}$, which reduced to $0.55 \mathrm{~cm}^{2}$ at the end of week 6 [21]. Gulati et al. (2014) concluded that honey dressings were more effective when compared to PVP-I in achieving complete healing; reducing wound surface area and pain, which increased the quality of life in the subjects with chronic wounds [21].

Zeleníková et al. (2019) [26] conducted a prospective interventional study aimed at determining the clinical effectiveness of honey dressings in the management of chronic wounds, mainly PUs and DFUs, in elderly persons receiving home care (Table 3) [26]. The sample comprised of forty $(n=40)$ patients. The patients were randomly designated into two groups, one receiving honey treatment and the other receiving conventional treatment, including PVP-I. PUs in patients were graded as stage II, III or IV [26]. At the end of the 90-day observational period, a difference in the mean wound size between groups was found to be significant [26]. The mean size of wounds was smaller in subjects with honey dressings in comparison to the controls (conventional dressings [CD]). In the honey-treated group, the mean wound size decreased from $15.7 \mathrm{~cm}^{3}$ to $6.0 \mathrm{~cm}^{3}$, whereas the wound size in the control group decreased from $16.9 \mathrm{~cm}^{3}$ to $9.8 \mathrm{~cm}^{3}$. The patients receiving conventional (PVP-I) dressings reported a higher pain intensity level compared to the experimental group throughout the study [26]. Wound odor was also assessed during this study, and it was found that the odor was absent in $75 \%$ of the wounds in the experimental group receiving the honey treatment at the end of the study in comparison to $10 \%$ of wounds in the control group treated with PVP-I [26].

\section{PUs}

A cross-sectional study by Khadanga et al. (2014) was conducted to compare the effectiveness of honey and PVP-I in wound healing in decubitus ulcers [27]. The study consisted of forty $(n=40)$ patients that presented with PUs over 10 days (Table 3). Twenty patients $(n=20)$ (Group A) were treated with honey dressings whereas the other 20 patients (Group B) received treatment using PVP-I dressings [27]. The mean wound size of each group was measured and recorded on day 1 and again on day 10. Group A exhibited a reduction in wound size from $32990.80 \pm 13284.29 \mathrm{~cm}^{3}$ to $2592.90 \pm 1276.05 \mathrm{~cm}^{3}$. Group B showed a reduction in wound size from $33840 \pm 12904.28 \mathrm{~cm}^{3}$ to $29431 \pm 1660.14 \mathrm{~cm}^{3}$ [27]. Though the size of the wound decreased with the use of the honey dressing, it was not considered as significant in the study. Group A and B both exhibited a reduced bacterial load within the wound bed [27].

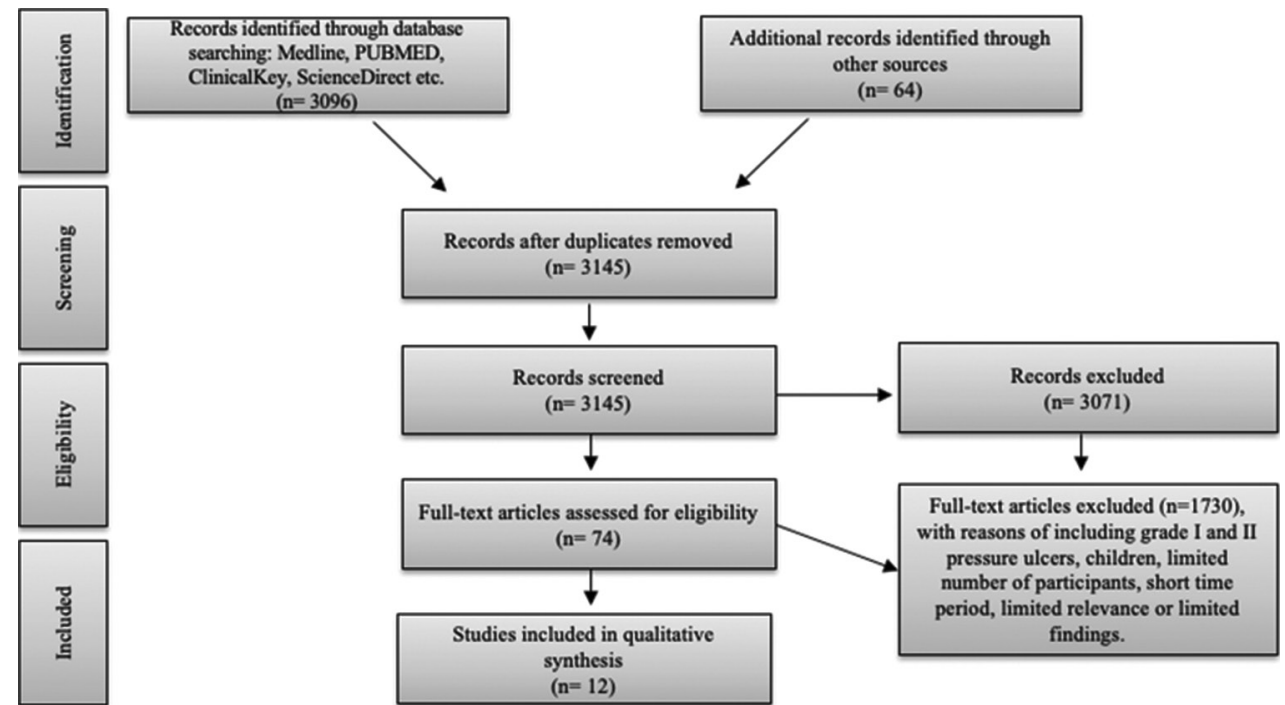

Fig. 1: Preferred reporting items for systematic reviews and meta-analyzes flow diagram 
Table 3: Overview of primary studies in PU and DFU treatment

\begin{tabular}{|c|c|c|c|c|c|c|}
\hline Author (s) & Title of study & Design of study & Wound etiology & $\begin{array}{l}\text { No. of } \\
\text { patients }\end{array}$ & Type of intervention & Outcome \\
\hline $\begin{array}{l}\text { Gulati et al. } \\
\text { (2014) [21] }\end{array}$ & $\begin{array}{l}\text { A Prospective } \\
\text { Randomized Study } \\
\text { to Compare the } \\
\text { Effectiveness of } \\
\text { Honey Dressing vs. } \\
\text { Povidone Iodine } \\
\text { Dressing in Chronic } \\
\text { Wound Healing }\end{array}$ & $\begin{array}{l}\text { Randomized } \\
\text { Controlled } \\
\text { Trial (RCT) }\end{array}$ & $\begin{array}{l}\text { Varied etiology- } \\
\text { PUs and DFUs } \\
\text { included }\end{array}$ & $n=45$ & $\begin{array}{l}\text { Sterilized } \\
\text { honey }(n=23) \text { vs. } \\
\text { PVP-I group }(n=22)\end{array}$ & $\begin{array}{l}\text { - Faster wound healing } \\
\text { was observed in wounds } \\
\text { dressed with honey in } \\
\text { comparison to PVP-I } \\
\text { - Honey was found to } \\
\text { reduce pain and increase } \\
\text { patient comfort }\end{array}$ \\
\hline $\begin{array}{l}\text { Zeleníková et al. } \\
\text { (2019) [26] }\end{array}$ & $\begin{array}{l}\text { Applying honey } \\
\text { dressings to } \\
\text { non-healing wounds } \\
\text { in elderly persons } \\
\text { receiving home care }\end{array}$ & RCT & $\begin{array}{l}\text { Varied } \\
\text { etiology- PUs } \\
\text { and DFUs } \\
\text { included }\end{array}$ & $n=40$ & $\begin{array}{l}\text { Manuka } \\
\text { honey }(\mathrm{MH})(\mathrm{n}=20) \\
\text { vs. Conventional } \\
\text { dressings with } \\
\text { PVP-I (CD) }(\mathrm{n}=20)\end{array}$ & $\begin{array}{l}\text { - Honey accelerated } \\
\text { wound healing } \\
\text { - Honey was superior in } \\
\text { the reduction of wound } \\
\text { size and caused less pain } \\
\text { - Honey was found to } \\
\text { reduce the malodor of } \\
\text { chronic wounds better } \\
\text { than wounds treated } \\
\text { with PVP-I }\end{array}$ \\
\hline $\begin{array}{l}\text { Khadanga et al. } \\
\text { (2014) [27] }\end{array}$ & $\begin{array}{l}\text { Effects of Topical } \\
\text { Honey Dressing in } \\
\text { Decubitus Ulcer }\end{array}$ & $\begin{array}{l}\text { Cross-sectional } \\
\text { study }\end{array}$ & PUs & $n=40$ & $\begin{array}{l}\text { Honey group } \\
\text { A }(n=20) \text { vs. } \\
\text { PVP-I group } B(n=20)\end{array}$ & $\begin{array}{l}\text { - Honey was found to } \\
\text { be more effective in } \\
\text { the contraction of the } \\
\text { wound surface although } \\
\text { it was not considered as } \\
\text { significant }\end{array}$ \\
\hline $\begin{array}{l}\text { Choudhary et al. } \\
\text { (2015) [28] }\end{array}$ & $\begin{array}{l}\text { Comparative study of } \\
\text { honey and betadine } \\
\text { in chronic ulcer } \\
\text { healing }\end{array}$ & RCT & $\begin{array}{l}\text { Varied etiology- } \\
\text { PUs }(n=9) \text { and } \\
\text { DFUs }(n=9) \\
\text { included }\end{array}$ & $\mathrm{n}=30$ & $\begin{array}{l}\text { Honey group } \\
\text { A ( } n=15) \text { vs. } \\
\text { PVP-I group B } \\
(n=15)\end{array}$ & $\begin{array}{l}\text { - Honey was reported to } \\
\text { be superior in terms of } \\
\text { wound healing rate } \\
\text { - Honey was more } \\
\text { effective in exudate } \\
\text { removal and reduction } \\
\text { of oedema }\end{array}$ \\
\hline $\begin{array}{l}\text { Shukrimi et al. } \\
\text { (2008) [29] }\end{array}$ & $\begin{array}{l}\text { A comparative study } \\
\text { between honey and } \\
\text { Povidone-iodine as } \\
\text { dressing solution } \\
\text { for Wagner type II } \\
\text { diabetic foot ulcers }\end{array}$ & RCT & DFUs & $n=30$ & $\begin{array}{l}\text { Pure honey vs. } \\
\text { PVP-I (10\%) }\end{array}$ & $\begin{array}{l}\text { - Honey reduced oedema } \\
\text { and odor. } \\
\text { - Honey dressing } \\
\text { changes were less } \\
\text { painful. } \\
\text { - Wounds treated with } \\
\text { honey exhibited reduced } \\
\text { bacterial colonization }\end{array}$ \\
\hline $\begin{array}{l}\text { Kamaratos et al. } \\
\text { (2012) [30] }\end{array}$ & $\begin{array}{l}\text { Manuka } \\
\text { honey-impregnated } \\
\text { dressings in the } \\
\text { treatment of } \\
\text { neuropathic diabetic } \\
\text { foot ulcers }\end{array}$ & RCT & $\begin{array}{l}\text { Neuropathic } \\
\text { DFUs }\end{array}$ & $n=63$ & $\begin{array}{l}\text { MH }(n=32) \text { vs. } \\
\text { CD }(n=31)\end{array}$ & $\begin{array}{l}\text { - Bacterial colonization } \\
\text { decreased in the } \\
\text { honey-treated group } \\
\text { - Honey was } \\
\text { recommended as a } \\
\text { cost-effective alternative } \\
\text { as it reduces the length } \\
\text { of hospital stay }\end{array}$ \\
\hline $\begin{array}{l}\text { Agarwal } \\
\text { et al. (2015) [31] }\end{array}$ & $\begin{array}{l}\text { A control } \\
\text { clinical trial of } \\
\text { honey-impregnated } \\
\text { and Povidone-iodine } \\
\text { dressings in the } \\
\text { treatment of diabetic } \\
\text { foot ulcers among } \\
\text { Northern Indian } \\
\text { subjects }\end{array}$ & RCT & DFU's & $n=36$ & $\begin{array}{l}\text { Honey group A vs. } \\
\text { PVP-I group B }\end{array}$ & $\begin{array}{l}\text { - Honey was able to } \\
\text { reduce bacterial load } \\
\text { and infection in the } \\
\text { wound } \\
\text { - Honey treatment } \\
\text { caused less pain } \\
\text { experienced by the } \\
\text { patients } \\
\text { - Honey reduced } \\
\text { oedema of the wound } \\
\text { and reduced discharge } \\
\text { released }\end{array}$ \\
\hline
\end{tabular}


Table 3: (Continued)

\begin{tabular}{|c|c|c|c|c|c|c|}
\hline Author (s) & Title of study & Design of study & Wound etiology & $\begin{array}{l}\text { No. of } \\
\text { patients }\end{array}$ & Type of intervention & Outcome \\
\hline $\begin{array}{l}\text { Hammouri } \\
(2004)[32]\end{array}$ & $\begin{array}{l}\text { The role of honey in } \\
\text { the management of } \\
\text { diabetic foot ulcers }\end{array}$ & RCT & DFUs & $n=200$ & $\begin{array}{l}\text { Honey group } \\
\text { A }(n=100) \text { vs. } \\
\text { PVP-I/Hydrogen } \\
\text { peroxide group } \\
B(n=100)\end{array}$ & $\begin{array}{l}\text { - Honey was faster in } \\
\text { eradicating infection } \\
\text { - Honey reduces the } \\
\text { length of hospital stay } \\
\text { - Honey dressings } \\
\text { provided faster wound } \\
\text { healing and reduced the } \\
\text { rate of amputation }\end{array}$ \\
\hline $\begin{array}{l}\text { Tsang et al. } \\
\text { (2017) [33] }\end{array}$ & $\begin{array}{l}\text { A Pilot Randomized, } \\
\text { Controlled Study of } \\
\text { Nanocrystalline } \\
\text { Silver, Manuka Honey, } \\
\text { and Conventional } \\
\text { Dressing in Healing } \\
\text { Diabetic Foot Ulcer }\end{array}$ & RCT & DFUs & $\mathrm{n}=31$ & $\begin{array}{l}\text { MH }(n=10) \text { vs. } \\
\text { Nanocrystalline } \\
\text { silver }(N A g)(n=11) \\
\text { and } \\
\text { CD }(n=10)\end{array}$ & $\begin{array}{l}\text { - NAg is potentially } \\
\text { better than MH and CD } \\
\text { in DFU treatment } \\
\text { - MH is an effective } \\
\text { and safe alternative } \\
\text { antiseptic for DFU } \\
\text { treatments } \\
\text { - MH- and nAg-treated } \\
\text { groups exhibited a } \\
\text { significant decrease } \\
\text { in the microbial } \\
\text { colonization of the } \\
\text { wound } \\
\text { - Patients treated with } \\
\text { MH dressings exhibited } \\
\text { fewer adverse effects in } \\
\text { comparison to NAg or } \\
\text { CD treatment }\end{array}$ \\
\hline $\begin{array}{l}\text { Jan et al. } \\
(2012) \\
{[34]}\end{array}$ & $\begin{array}{l}\text { Comparison of } \\
\text { conventional pyodine } \\
\text { dressing with honey } \\
\text { dressing for the } \\
\text { treatment of diabetic } \\
\text { foot ulcers }\end{array}$ & $\begin{array}{l}\text { Quasi-experimental } \\
\text { study }\end{array}$ & DFUs & $n=100$ & $\begin{array}{l}\text { Honey group }(n=50) \\
\text { vs. } \\
\text { Pyodine }(n=50)\end{array}$ & $\begin{array}{l}\text { - A faster recovery time } \\
\text { was observed in wounds } \\
\text { treated with honey in } \\
\text { comparison to pyodine } \\
\text { group } \\
\text { - Honey dressing } \\
\text { provided faster wound } \\
\text { healing than the pyodine } \\
\text { dressing and reduced } \\
\text { the amputation rate }\end{array}$ \\
\hline $\begin{array}{l}\text { Ur-Rehman et al. } \\
\text { (2013) [35] }\end{array}$ & $\begin{array}{l}\text { Comparison } \\
\text { between honey and } \\
\text { Povidone-iodine/ } \\
\text { normal saline } \\
\text { dressing for } \\
\text { management of } \\
\text { Wagner's grade s I \& } \\
\text { II diabetic foot ulcers }\end{array}$ & RCT & DFUs & $n=60$ & $\begin{array}{l}\text { Honey group }(n=50) \\
\text { vs. } \\
\text { PVP-I/saline } \\
\text { group }(n=50)\end{array}$ & $\begin{array}{l}\text { - Honey dressings } \\
\text { were more effective in } \\
\text { reducing wound size } \\
\text { in comparison to the } \\
\text { PVP-I/saline dressing }\end{array}$ \\
\hline $\begin{array}{l}\text { Mukherjee et al. } \\
\text { (2018) [36] }\end{array}$ & $\begin{array}{l}\text { A Comparative Study } \\
\text { of Effectiveness } \\
\text { of Honey and } \\
\text { Povidone-iodine in } \\
\text { Healing of Surgical } \\
\text { Wound }\end{array}$ & $\begin{array}{l}\text { A longitudinal } \\
\text { non-randomized }\end{array}$ & PUs and DFUs & $n=100$ & $\begin{array}{l}\text { Honey group } \\
\text { A ( } \mathrm{n}=50)(50 \% \text { PUs } \\
\text { and DFUs) } \\
\text { PVP-I group } \\
\text { B (n = 50) (52\% PUs } \\
\text { and DFUs) }\end{array}$ & $\begin{array}{l}\text { - Honey dressings } \\
\text { reduced the degree of } \\
\text { pain experienced by } \\
\text { patients in comparison } \\
\text { to PVP-I dressings } \\
\text { - Honey dressings } \\
\text { accelerated wound } \\
\text { healing } \\
\text { - Honey treatment } \\
\text { provided better patient } \\
\text { comfort in comparison } \\
\text { to PVP-I treatment }\end{array}$ \\
\hline
\end{tabular}

A prospective, randomized trial by Choudhary et al. (2015) aimed to compare the healing of various chronic ulcers, including PUs and DFUs, with the application of honey and betadine (PVP-I) dressings (Table 3) [28]. The study focused on analysing the efficacy of honey in wound healing. The study comprised of thirty patients $(n=30)[28]$ that were divided equally into two groups: Group A that received the honey dressing and Group $B$ that received the betadine dressing. The trial was conducted over a period of 1 year. Of the 30 patients, 9 patients presented with PUs and 9 presented with DFUs, with 4 allocated to Group A and 5 to Group B, respectively. At the time of admission, the mean wound score for the patients with PUs in Group A was $14.5 \pm 3.3 \mathrm{~cm}^{2}$ and after 2-weeks of treatment, the wound score had reduced to $6 \pm 5.3 \mathrm{~cm}^{2}$ [28]. In comparison, the admission score for Group B was $14.4 \pm 2.6 \mathrm{~cm}^{2}$ and $6 \pm 3.8 \mathrm{~cm}^{2}$, respectively. The mean wound score for the patients with 
DFUs in Group A at the time of admission was $15.8 \pm 4.1 \mathrm{~cm}^{2}$ and after 2-weeks of treatment, the wound score had reduced to $7.4 \pm 2.7 \mathrm{~cm}^{2}$ [28]. In comparison, the admission score for Group B was $15.7 \pm 2.0 \mathrm{~cm}^{2}$ and $10.25 \pm 4.0 \mathrm{~cm}^{2}$, respectively. In all patients treated with honey, $80 \%$ of patients exhibited improved wound healing whereas $60 \%$ of patients treated with betadine exhibited improved wound healing [28].

\section{DFUs}

Shukrimi et al. (2008) conducted a randomized clinical trial to compare the effect of non-sterile, pure honey with PVP-I in 30 patients with DFUs (Table 3) [29]. The study was divided into two study arms; a honey dressing group and a PVP-I dressing group. The patients were divided equally between the two groups and physicians carefully monitored the blood glucose levels of these patients [29]. The study focused on analyzing the eradication of bacterial organisms such as Staphylococcus species (sp)., Streptococcus sp., Pseudomonas sp., Bacteroides, Enterococcus, and Acinetobacter sp., and Escherichia coli, present in the ulcers [29]. The study concluded that wounds infected with Staphylococcus sp. and Streptococcus sp. treated with honey, exhibited reduced bacterial colonization [29]. However, ulcers infected with Bacteroides and Enterococcus did not show a reduction in bacterial load. The honey treated group also showed a reduced mean wound healing time of 14.4 days in comparison to the PVP-I group, which required 15.4 days [29].

A study conducted by Kamaratos et al. (2014) analyzed the woundhealing effects of MH-impregnated dressings (MHID) in neuropathic DFUs (NDFUs) and MHID's ability to disinfect ulcers [30]. Sixty-three type two (II) diabetic patients $(n=63)$ were randomly assigned into two groups (Table 3); 32 patients were treated with MHID and 31 patients were treated with CD [30]. The study was conducted over a period of 16-weeks and patients were administered empirical antibiotic monotherapy in patients with severe infections. The majority of the MHID-treated group (97\%) exhibited complete healing in comparison to the CD group (90\%). In addition, there was a significant difference in the mean duration of healing between the two groups. The NDFUs in the MHID-treated group took 27-35 days to heal whereas CD-treated NDFUs took 40-46 days to heal completely [30]. Both groups exhibited mixed bacterial growth in the wounds, however, $78.13 \%$ of MHID-treated patients presented with sterile wounds within the $1^{\text {st }}$ week of treatment in comparison to $35.5 \%$ of CD-treated patients [30]. Evidence from this study showed that none of the MHID patients required antibiotic treatment while 9 patients in the CD-treated group, did [30].

A controlled clinical trial study conducted by Agarwal et al. (2015) compared the efficacy of honey with PVP-I as a dressing material in the management of DFUs in 36 patients (Table 3) [31]. All patients all presented with non-insulin-dependent DM with Wagner grade-II DFUs. The patients were divided into two groups, namely, Group A, the honey impregnated dressing group and Group B, the PVP-I dressing group [31]. The study was conducted over a period of one (1) year. The blood glucose levels of these patients were kept optimum under supervision. Streptococcus sp. Staphylococcus sp., Pseudomonas, Acinetobacter, E. coli, and polymicrobial infections were isolated from the wounds of these patients [31]. At the end of the study, a reduced bacterial load was recorded in the wounds of both groups, indicating that honey was able to reduce infection. In the honey-treated group, wound healing took an average of 14.2 days whereas wounds treated with the standard dressing took 15.5 days to heal [31]. All patients in the honey Group A experienced reduced pain (pain score of 5.3) during treatment in comparison to Group B (pain score of 6.6). the patients also presented with reduced oedema. In addition, a reduced amount of discharge was recorded with honey-treated wounds [31].

Honey is often used in combination with other dressings to further enhance its activities. In a study performed by Hammouri (2004) [32], honey/saline dressings were compared to PVP-I/hydrogen peroxide dressings (applied in a 3:1 ratio) in the management of DFUs (Table 3). The study consisted of two hundred $(n=200)$ patients and ran over a period of 5 years. The following parameters namely, healing, hospital stay, and cost, were analyzed. The patients were divided equally into two groups $(n=100)$ [32]. The study noted that the patients treated with the honey dressings had a shorter hospital stay (13 days) in comparison to the patients treated with PVP-I (23 days). The authors also noted that 10 patients from the PVP-I group failed to respond to treatment and were therefore treated with the honey dressings instead. Eight (8) of these wounds exhibited dramatic improvement in healing, however, the remaining two had to undergo amputation [32]. Bacterial culture swabs were taken weekly from the wounds of the patients and it was found that 15 of the patients in the honey dressing group exhibited clean wounds after just 7 days of treatment [32].

A RCT was conducted by Tsang et al. (2017) [33] to examine the effectiveness of nanocrystalline silver (nAg) against $\mathrm{MH}$ and $\mathrm{CD}$ in the healing of severe DFUs in terms of ulcer healing, infection and inflammation (Table 3) [33]. The study was conducted over 12 weeks with nine observation appointments throughout [33]. Thirty-one $(n=31)$ patients were randomized into three groups namely, the $\mathrm{nAg}$ group $(n=11)$, the $M H$ group $(n=10)$, and the CD group $(n=10)$ [33]. The authors recorded that the nAg-treated group exhibited the highest wound healing rate of $(81.8 \%$, with the $\mathrm{MH}$-treated group exhibiting a $50 \%$ wound healing rate and the CD-treated group with $40 \%$ [33]. The amount of microbial colonization located in the wounds of the three groups decreased over the 12 weeks. The authors noted that the $\mathrm{MH}$ and nAg-treated groups exhibited a significant decrease in the number of microorganisms present in the wound [33]. In the CD-treated group, 4 patients experienced severe adverse effects in comparison to 1 patient in each of the $\mathrm{nAg}$ and $\mathrm{MH}$-treated groups, who experienced calf swelling and a generalized blister, respectively [33].

Jan et al. (2012) conducted a quasi-experimental study to compare conventional pyodine dressings (Group A) to honey dressings (Group B) in 100 patients with diabetes and Wagner grade I-VI DFUs (Table 3) [34]. The study was conducted over a 1-year period. Patients were divided equally between the two groups [34]. The groups were treated with the respective dressings daily and blood glucose levels were properly monitored in the diabetic patients throughout the study [34]. The authors recorded that in 30\% of patients in Group A, healed in the first $2-4$ weeks of treatment while $44 \%$ healed in weeks $8-10$. In Group B, $60 \%$ of patients healed in the first $2-4$ weeks of treatment whereas $6 \%$ of patients healed in weeks $8-10$, therefore indicating that the recovery time was faster in Group B in comparison to Group A [34]. The amputation rate was lower in patients in Group B (28\%) in comparison to patients in Group A (34\%) [34]. The authors raised the concern that the strong bactericidal effects of pyodine on wound healing may be a common explanation for the delay in wound healing, as the preparation may have a harmful effect on healing tissue [34].

A study conducted by Ur-Rehman et al. (2013) aimed to compare the wound healing properties of honey to PVP-I/saline dressings in Wagner grade I and II DFUs (Table 3) [35]. The study was conducted over six (6) months and included 60 patients that were randomly assorted into two equal numbered groups. The authors measured the percent decrease in wound size and analyzed the antimicrobial effects of both dressings. The decrease in wound size of the honey treated group $(80.81 \pm 17.27 \%)$ was better when compared to the PVP-I treated group $(54.63 \pm 3.42 \%)[35]$.

Mukherjee et al. (2018) conducted a study to compare the efficacy of honey and PVP-I in different chronic wounds (Table 3) [36]. DFU and PU wounds made up 50\% in the honey-treated group and 52\% in the PVP-I dressing group, respectively. The study comprised of 100 patients that were equally divided into a honey-treated group (Group A) and a PVP-I treated group (Group b) [36]. The authors noted the average pain score experienced by patients after 1 month of treatment and then again after 3 months. The honey treated group experienced a 2.42 point pain score at one month, which then reduced to 0.16 at three months [36]. The surface area of these wounds also reduced from $1.98 \mathrm{~cm}^{2}$ to $0.27 \mathrm{~cm}^{2}$ after 
3 months [36]. In comparison to the PVP-I treated group, the average pain score at 1 -month post-treatment was 2.58 and then 0.76 at 3 months. The surface area of these wounds did not reduce as much as those in the honey treated group, as they reduced from $2.42 \mathrm{~cm}^{2}$ to $0.51 \mathrm{~cm}^{2}$ [36].

The results of the studies included in this review are summarized below (Table 3).

\section{DISCUSSION}

Honey is an ancient remedy that has been used for hundreds of years for the treatment of infected wounds and to accelerate wound healing [19]. The role of honey as an antiseptic dressing material has been studied by several researchers [21-36]. PUs and DFUs present with polymicrobial infections were found to delay wound healing and edema, placing a patient at risk for serious complications. In addition, these ulcers also cause increased pain and discomfort experienced by the patient and present with malodor. This review aimed to investigate the efficacy and safety of honey as an alternative to standard antiseptic care in the treatment of PUs and DFUs in adults.

Chronic wounds are defined by remaining in the inflammatory phase of the wound healing process [25]. This delays the ability of a wound to heal and progress to the next phase. Honey was shown to exhibit antiinflammatory effects which in turn, reduced the wound healing time. This can be explained through the dual effect of honey on the inflammatory response [25]. Honey suppresses the production of inflammatory cells at the wound site, and it stimulates the production of proinflammatory cytokines, such as tumor necrosis factor-alpha, interleukin (IL)-1 $\beta$ or IL-6, involved in the normal wound healing process [25]. Honey was found to exhibit its anti-inflammatory and wound-promoting effects by accelerating the wound healing rate in comparison to other antiseptics, such as PVP-I. These findings were supported by studies conducted by Gulati et al. (2014), Zeleníková et al. (2019), Choudhary et al. (2015), Jan et al. (2012), and Mukherjee et al. (2018) [21,26,28,34,36]. The authors mentioned that faster wound healing was observed in PUs and DFUs when dressed with honey $[21,26,28,34,36]$. In the study conducted by Mukherjee et al. (2018), honey-treated chronic wounds exhibited significant wound closure and healing ( $86 \%$ of patients) in a 3 month period when treated with honey in comparison to PVP-I treatment ( $50 \%$ of patients) [36]. Thus, honey had significantly better wound healing in comparison to conventional PVP-I [36]. Khadanga et al. (2014) noted that honey-treated wounds exhibited a reduction in the bacterial load and the size of the PU was significantly reduced in these patients [27].

Gulati et al. (2014), Zeleníková et al. (2019), Khadanga et al. (2014), Mukherjee et al. (2018), and Choudhary et al. (2015) recorded a reduction in the mean/median surface area of honey-treated wounds, thus exhibiting honey's ability to promote wound closure [21,26-28,36]. The increased wound healing may be due to the ability of honey to promote fibroblast proliferation, collagen deposition and tissue regeneration [23]. These processes are required for wound closure and healing. Honey rapidly replaces slough with granulation tissue and promotes rapid epithelialization [23] which is achieved by fibroblast and epithelial cell growth. These cells grow at the epidermal layer of the skin and are involved in wound closure and skin formation [23]. The sugary wet environment that honey provides in the wound bed improves local nutrition and epithelialization to the skin, thus increasing tissue granulation and closure [20,23]. A study by Shukrimi et al. (2008) found that DFU wounds granulated well and that the ulcers were free of infection at the end of the study, which shows that the process of wound healing was more effective [18]. Honey was found to promote collagen synthesis and storage due to the presence of nitric oxide (NO) in honey [23] which promotes vasodilation, angiogenesis, upregulates vascular homeostasis, and promotes tissue healing [21,23].

A study conducted by Gulati et al. (2014) reported that two patients had to be removed from the trial owing to the toxic effects associated with the use of PVP-I such as skin irritation. The patients treated with honey exhibited no adverse effects during treatment [21]. Mukherjee et al. (2018) noted that none of the patients experienced adverse effects when treated with honey in comparison to PVP-I treated patients [36]. These findings support the fact that PVP-I does not satisfy all the criteria of an ideal antiseptic agent and is limited in its application because of its iodine content [23-26]. Tsang et al. (2017) also recorded that only one patient in the MH-treated group for DFU treatment exhibited an adverse effect namely, a generalized blister [36].

In several of the studies analyzed, a 'Wound Score system' was used when analyzing the wound healing rate of PUs and DFUs in response to treatment [14]. The system quantifies the severity of the wound as "healthy" (7.5 to 10 points), "problematic" (3.5 to 7 points), or "unavailing" (0 to 3 points) and provides the basis for wound management strategies [14]. In the study conducted by Choudhary et al. (2015), the patients treated with honey dressings showed a $20 \%$ higher wound healing rate in comparison to those treated with betadine [28]. Jan et al. (2012) recorded that more than $30 \%$ of the patients in the honey-treated group presented with wound healing in week 2-4 of treatment, in comparison to the pyodine-treated group [34]. More patients in the honey-treated group presented with successful healing toward the end of the study period in comparison to the pyodine-treated group [34]. This is owing to honey's acidic pH that increases oxygen release from hemoglobin and stimulates the activity of macrophages and fibroblasts, which are involved in tissue regeneration [22,23]. Honey's ability to improve wound healing was also recorded in the study by Zeleníková et al. (2019) which concluded that the application of honey dressings in non-healing wounds resulted in faster healing and wound size reduction [26]. Among the patients receiving honey dressings, $80 \%$ presented with completely healed wounds within 3 months in comparison to $30 \%$ of the control group [26]. Honey's antioxidant and anti-inflammatory effects were found to accelerate the wound healing process. Flavonoids are phytochemicals found within medical grade honey that inhibit the formation of superoxide free radicals which protects infected tissues from further damage [23]

Evidence from studies conducted by Khadanga et al. (2014), Shukrimi et al. (2008), and Kamaratos et al. (2014) showed a reduction in bacterial growth or colonization within the wound bed in the honeytreated groups $[27,29,30]$. Honey-impregnated wound dressings seem to disinfect wounds and provide a lower bacterial count to ensure an optimum environment for healing. These studies confirmed honey's ability to eradicate infection $[27,29,30]$. Honey contains low concentrations of $\mathrm{H}_{2} \mathrm{O}_{2}$ that promotes fibroblast proliferation and collagen deposition, which indirectly removes bacteria in the wound bed [23]. Honey stimulates angiogenesis for proliferating cells thus providing blood, oxygen and nutrients to neutrophils, and other cells, involved in the inflammatory and wound healing process [23]. Honey's high sugar content draws fluid out of the wound bed by osmosis which dehydrates bacteria and damages their cell walls, leading to cell death $[22,23]$. Its acidic $\mathrm{pH}$ inhibits the growth of bacteria within the wound as bacteria require a more alkaline environment to survive. Honey's thick consistency makes it a successful barrier from the external environment and foreign material [22,23]. It also prevents cross-infection as it creates a moist antibacterial environment that rapidly eliminates bacteria in the wound [23]. All of these mechanisms result in the reduced incidence of infection and the eradication of bacteria in the wound bed [23-26]. A study conducted by Kamaratos et al. (2014) showed that no additional antibiotic treatment was needed when treating patients with $\mathrm{MH}$ dressings as they recorded a rapid clearance of the bacterial load in DFUs with the use of honey alone [30].

Amputations are often necessary for diabetic patients that present with DFUs, due to restricted blood flow to the lower limb and uncontrollable bacterial infections. Hammouri (2004) and Jan et al. (2012) both mentioned that the amputation rate in honey-treated DFU patients in the respective studies, was significantly lower than those treated with CD $[32,34]$. This supports the theory that honey can stimulate angiogenesis in the wounded area and increase blood flow, thus 
promoting wound healing [19]. In addition, honey's antibacterial properties eradicate microbial colonization in the wound bed, therefore preventing severe infection that may lead to amputation [23-26].

PUs and DFUs present with slow healing owing to infection, ischemia and neuropathy [14]. Shukrimi et al. (2008), Choudhary et al. (2015), and Agarwal et al. (2015) concluded that honey aids in reducing swelling and water retention in the wound bed and aids in the reduction of wound discharge $[28,29,31]$. This is owing to honey's ability to reduce oedema as its high osmolarity allows it to absorb water [22-24] which improves lymphatic drainage and blood circulation, thereby improving wound healing $[22,23]$. Its high osmotic pressure content enables it to be successful at wound debridement as it draws fluid out of the wound bed, thus, reducing the amount of exudate present [22-24]. This further relieves pressure from the wound bed and allows for proinflammatory cells to be recruited efficiently to the wound site thus aiding in the process of healing.

Gulati et al. (2014), Zeleníková et al. (2019), Shukrimi et al. (2008), Agarwal etal.(2015), and Mukherjee etal.(2018) mentioned thatdressing changes with honey were less painful for patients $[21,26,29,31,36]$. This can be attributed to the ability of honey to maintain the moisture level of wounds without adhesion to the surface and increasing blood and nutrient supply to the open wound [18]. As a result, treatment of PUs and DFUs with honey will provide more comfort to the patient and will make the healing process easier and efficient [18]. Mukherjee et al. (2018) noted that patients treated with honey dressings experienced significantly less pain (reduced pain score by 2.26 points) over a period of 3 months in comparison to patients treated with PVP-I dressings (reduced pain score by 1.82 points) [36].

Honey was found to reduce the pungent smell associated with PUs and DFUs, in studies conducted by Shukrimi et al. (2008) and Zeleníková et al. (2019) [26,29]. This is achieved by honey's ability to neutralise odor-inducing compounds (sulphur dioxide and NO) released by bacteria within the wound bed as well as honey's debriding activity and its ability to remove dead and necrotic tissue [23-25]. In addition, honey contains glucose which provides an alternative nutrient source for bacteria within the wound bed which results in the production of lactic acid as a waste product rather than sulfur-containing compounds [22,23].

Kamaratos et al. (2014), Khadanga et al. (2014), and Shukrimi et al. (2008) all highlighted that there were significant economic benefits in using honey in DFU wound care $[27,29,30]$. Hammouri (2004) noted that the introduction of honey dressings as a method of treating DFUs, reduced the cost of treatment by $50 \%$ [32]. DFUs require long periods to heal and are associated with financial implications and long-term hospital stays. As a result, the overall cost associated with the use of wound dressings containing honey may be more cost-effective and economical in comparison to standard treatment [29].

The authors in the abovementioned studies also noted that honey dressings were easier to apply, with less damage to granulating tissue, compared to those of conventional treatment [32]. The ease of its application and its easy availability makes it a suitable first-aid treatment for PUs and DFUs and can be managed by novice clinicians.

\section{LIMITATIONS}

Additional research will need to be conducted to support the findings in this review. The articles included in this study presented with limited population sizes that could give rise to bias. Several of the authors did not record results periodically, which may result in inaccuracies in the results. Several of the studies were conducted over short time periods or the study failed to mention the length of treatment, which brings into question whether honey significantly accelerates the wound healing process in comparison to standard antiseptic care. Mixed etiologies of wounds were included in several studies. This makes treatment difficult as different wounds take different time periods to heal; treatment options may differ and the mixing wounds in this way could have an impact on the validity of the analysis.

\section{RECOMMENDATIONS}

More randomized studies on larger population sizes and stratifying results with wounds of the same etiology and heterogeneity, need to be carried out. Studies with pre-specified outcome measures and methods, need to be compiled and carried out over appropriate timeframes to confirm the advantages of honey in the treatment of PUs and DFUs. Chronic wounds can take up to 3 months to heal; therefore, a treatment period of 3 months or longer is recommended. This will provide more conclusive evidence which can be applied to the general population.

\section{CONCLUSION}

Quality research on the clinical role of honey in the treatment of PUs and DFUs is extremely limited and is compounded by the complexity of wound care and the recruitment of a large number of the patients with identical wound etiologies. The relevant studies and trials that were found did, however, support the use of honey as an effective and safe alternative to antiseptics in the treatment of PUs and DFUs. Honey was found to be effective in treating these chronic wounds as it exhibited antimicrobial, antioxidant, and anti-inflammatory effects. It was found to promote epithelialization and wound-debriding effects as well as reducing the pain experienced by the patient. The foulodor associated with chronic PUs was reduced when treated with the medical grade honey. Honey dressings were found to be highly effective in the successful healing of chronic ulcers when compared to standard antiseptic care, especially in the trials that analyzed PVP-I. If the appropriate wound dressings are used in the patients with PUs and DFUs, their quality of life can be greatly improved because of a decrease in pain and discomfort, while shorter hospital visits will have a positive effect on the financial aspect thereof. As current literature on this topic is limited, further research is warranted. This review can serve as a foundation for future studies to better understand the safety and efficacy of honey to reduce the bacterial burden in the wound bed of PUs and DFUs as well as its wound healing effects in comparison to standard antiseptics.

\section{ACKNOWLEDGMENTS}

The review authors gratefully acknowledge the various researchers that completed the abovementioned studies and the study patients.

\section{AUTHORS' CONTRIBUTIONS}

G.F. Pereira: Content curation; Data identification and synthesis; Methodology; Project administration; Visualization; Roles/ Writing - original draft; Writing - review and editing.

M Balmith: Formal analysis; Investigation; Methodology; Project administration; Supervision; Validation; Visualization; Writing - review and editing.

M Nell: Conceptualization; Formal analysis; Investigation; Methodology; Project administration; Supervision; Validation; Visualization; Writing - review and editing.

\section{CONFLICTS OF INTEREST}

Authors declare no conflict of interest.

\section{AUTHORS FUNDING}

Authors did not receive any funding.

\section{REFERENCES}

1. Smith ME, Totten A, Hickam DH, Rongwei F, Wasson N, Basmah R, et al. Pressure ulcer treatment strategies: A systematic comparative effectiveness review. Ann Intern Med 2013;159:39-50.

2. Van Devender Y, Bester P. Holistic care for patients living with chronic 
wounds. Wound Healing Southern Afr 2015;8.

3. Anders J, Heinemann A, Leffmann C, Leutenegger M, Pröfener F, von Renteln-Kruse W. Decubitus ulcers: Pathophysiology and primary prevention. Dtsch Arztebl Int 2010;107:371-81.

4. Zhang P, Lu J, Jing Y, Tang S, Zhu D, Bi Y. Global epidemiology of diabetic foot ulceration: A systematic review and meta-analysis. Ann Med 2017;49:106-16.

5. Chronic Wounds; c2008-2021. Available from: https://www. woundsource.com/patientcondition/chronic-wounds. [Last accessed on 2021 Apr 26].

6. Alex R, Ratnaraj B, Winston B, Samson Devakiruba DN, Samuel C, John $\mathrm{J}$, et al. Risk factors for foot ulcers in patients with diabetes mellitus-a short report from vellore, South India. Indian J Community Med 2010;35:183-85.

7. Gethin G. The role of antiseptics in pressure ulcer management. Nurs Stand 2011;26:53-60.

8. Pressure Ulcers; c2020. Available from: https://www.physio-pedia. com/Pressure_Ulcers. [Last accessed on 2021 Mar 02]

9. A Guide to Pressure Ulcer Prevention and Management from the Victoria Quality Control Australia; c2004. Available from: http://www. elearning.health.vic.gov.au/PressureUlcerBasics/module1/topic2/ page11.htm. [Last accessed on 2021 Mar 02].

10. Alderden J, Rondinelli J, Pepper G, Cummins M, Whitney J. Risk factors for pressure injuries among critical care patients: A systematic review. Int J Nurs Stud 2017;71:97-114.

11. Bluestein D, Javaheri A. Pressure ulcers: Prevention, evaluation, and management. Am Fam Physician 2008;78:1186-94.

12. Bhattacharya S, Mishra RK. Pressure ulcers: Current understanding and newer modalities of treatment. Indian J Plast Surg 2015;48:4-16.

13. Here Are the Key Forces that Cause Pressure Ulcers; c1997. Available from: https://www.reliasmedia.com/articles/48517-here-are-the-keyforces-that-cause-pressure-ulcers. [Last accessed on 2021 Mar 02].

14. Diabetic Foot-risk Factors and Prevention; c2008-2021. Available from: https://www.woundsource.com/blog/diabetic-foot-risk-factorsand-prevention. [Last accessed on 2021 Apr 26].

15. Diabetic Foot Ulcers: Pathogenesis and Management; c2002. Available from: https://www.aafp.org/afp/2002/1101/p1655.html. [Last accessed on 2021 Apr 26].

16. Diabetic Foot Ulcers: Prevention, Diagnosis and Classification; c1998. Available from: https://www.aafp.org/afp/1998/0315/p1325.html. [Last accessed on 2021 Apr 26]

17. Guo S, Dipietro LA. Factors affecting wound healing. J Dent Res 2010;89:219-29.

18. Kruse I, Edelman S. Evaluation and treatment of diabetic foot ulcers. Clin Diabetes 2006;24:91-3.

19. Mandal MD, Mandal S. Honey: Its medicinal property and antibacterial activity. Asian Pac J Trop Biomed 2011;1:154-60.

20. Drosou A, Falabella A, Kirsner RS. Antiseptics on wounds: An area of controversy (part one). Wounds 2003;15:149-66.

21. Gulati S, Qureshi A, Srivastava A, Kataria K, Kumar P, Balakrishna
Ji A. A prospective randomized study to compare the effectiveness of honey dressing vs. Povidone iodine dressing in chronic wound healing. Indian J Surg 2014;76:193-8.

22. Does Honey Ever Go Bad? What You Should Know. Healthline; c2020. Available from: https://www.healthline.com/nutrition/does-honey-gobad. [Last accessed on 2021 Mar 10]

23. Vandamme L, Heyneman A, Hoeksema H, Verbelen J, Monstrey S. Honey in modern wound care: A systematic review. Burns 2013;39:1514-25.

24. Olas B. Honey and its phenolic compounds as an effective natural medicine for cardiovascular diseases in humans? Nutrients 2020;12:283.

25. Alvarez-Suarez JM, Gasparrini M, Forbes-Hernandez TY, Mazzoni L, Giampieri F. The composition and biological activity of honey: A focus on Manuka honey. Foods 2014;3:420-32.

26. Zeleníková R, Vyhlídalová D. Applying honey dressings to non-healing wounds in elderly persons receiving home care. J Tissue Viability 2019;28:139-43.

27. Khadanga S, Dugar D, Karuna T, Khetri R, Tim H, Ghata S, et al. Effects of topical honey dressing in decubitus ulcer. Asian J Med Sci 2015;6:99-110.

28. Choudhary KN, Soni P, Singh R. Comparative study of honey and betadine in chronic ulcer healing. J Evid Based Med 2015;2:6877-82.

29. Shukrimi A, Sulaiman AR, Halim AY, Azril A. A comparative study between honey and povidone iodine as dressing solution for Wagner Type II diabetic foot ulcers. Med J Malaysia 2008;63:44-6.

30. Kamaratos AV, Tzirogiannis KN, Iraklianou SA, Panoutsopoulos GI, Kanellos IE, Melidonis AI. Manuka honey-impregnated dressings in the treatment of neuropathic diabetic foot ulcers. Int Wound $\mathrm{J}$ 2014:11:259-63.

31. Agarwal S, Bhardwaj V, Singh A, Khan H, Goel S, Bhara M. A control clinical trial of honey-impregnated and povidone iodine dressings in the treatment of diabetic foot ulcers among Northern Indian subjects. Indian J Sci Res 2015;6:7-10.

32. Hammouri SK. The role of honey in the management of diabetic foot ulcers. J Res Med Sci 2004;11:20-2.

33. Tsang KK, Kwong EW, Shing-Shun To T, Chung JW, Wong TK. A pilot randomized, controlled study of nanocrystalline silver, manuka honey, and conventional dressing in healing diabetic foot ulcer. Evid-Based Compl Alt Med 2017:1-15.

34. Jan WA, Shah H, Khan M, Fayaz M, Ullah N. Comparison of conventional pyodine dressing with honey dressing for the treatment of diabetic foot ulcers. J Postgrad Med Inst 2012;26:402-7.

35. Ur-Rehman E, Afzal MO, Ali A, Qureshi AR, Rashid M. Comparison between honey and povidone-iodine/normal saline dressing for management of Wagner's grade s I and II diabetic foot ulcers. Pak J Med Health Sci 2013;7:1082-85.

36. Mukherjee R, Smanta S, Jha A, Srkar GP. A comparative study of effectiveness of honey and povidone iodine in healing of surgical wound. IJCMSR 2018;3:142-6. 